\title{
Anterior skull base meningiomas: surgery related hypothalamic sequalae. How to avoid?
}




\title{
Anterior skull base meningiomas: surgery related hypothalamic sequalae. How to avoid?
}

\author{
Ashraf El Badry, Ahmed Nageeb Taha \\ Neurosurgery Department, Faculty of Medicine, Mansoura University, EGYPT
}

\begin{abstract}
Introduction: Surgical: morbidities related to anterior skull base meningiomas are widely addressed in the literature and mostly related to tumor relations to cranial nerves and vascular structures in this challenging area. However; there is infrequent complications related to hypothalamic insult either from direct affection or via manipulation of vascular supply of this area. The aim of this study: is to address hypothalamic complications occurred after surgery for anterior skull base meningiomas, pitfalls in our surgical technique and the way to minimize such morbidities. Patients and methods: Retrospective study was conducted on all patients who did surgery for anterior skull base meningiomas in the neurosurgery department, Mansoura University during the period from 2011 to 2016. All the patients clinical and radiological data before and after surgery were analyzed. All patients who developed transient or permeant hypothalamic manifestation were included in this study and data regarding their tumor morphology, surgical technique and post-operative early and late imaging were assessed. Results: Among 93 patients who did surgery for anterior skull base meningiomas; 12 patients developed post-operative sequalae related to hypothalamic function. In 7 patients; tumor was recurrent and in 4 patients; conformal radiotherapy was given after the initial surgery. Complication was transient in 3 patients and permeant in 9 patients. 8 patients died from their hypothalamic sequalae. Early post-operative imaging showed hypothalamic infarction in 8 patients. Conclusion: Through reviewing these cases we can address the importance of many factors in the tumours especially size, morphology, recurrence who increase hypothalamic insults. Factors in surgery include preservation of arachnoid plain, perforators, meticulous dissection for minimize this complication.
\end{abstract}

\section{Introduction}

Anterior skull base meningiomas represent a challenge in the neurosurgical practice because of difficult anatomical orientation in addition to a required adequate training in frequent surgeries for long time to develop efficient learning curves for better surgical outcomes in such cases. Despite progressive advancement in skull base surgery and better anatomical understanding nowadays; surgery for those meningiomas still carry its potential risks due to very close relation to important 
neurovascular including the optic pathway, internal carotid artery (ICA) and its branches, the cavernous sinus, the orbit, the pituitary gland and hypothalamus (1,3,4,5,9,11). Moreover; the tumor itself has its own challenge including its size whatever small or large tumours (Figures 1,2), consistency and the vascularity.

The concept of surgery varies between two options: Optimistic and Realistic (It doesn't matter how the patient's post-operative images in relation to pre-operative ones (Figures 3, 4, 5,6 ) but what is his post-operative conditions.

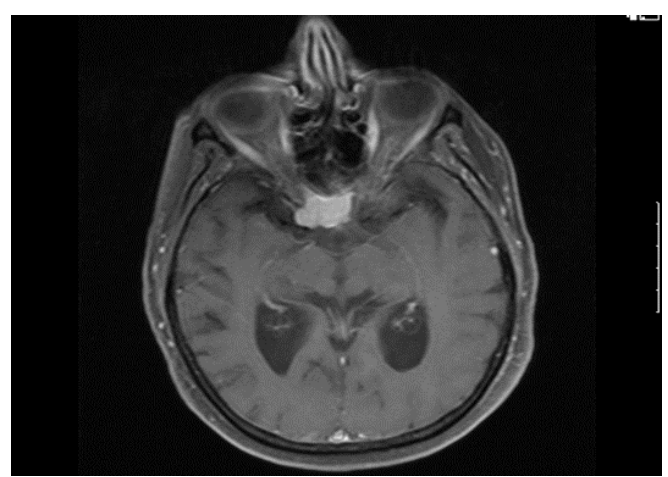

Figure 1 - MRI Brain T1WI axial cuts with contrast revealed homogenous enhanced small sellar and suprasellar tumor

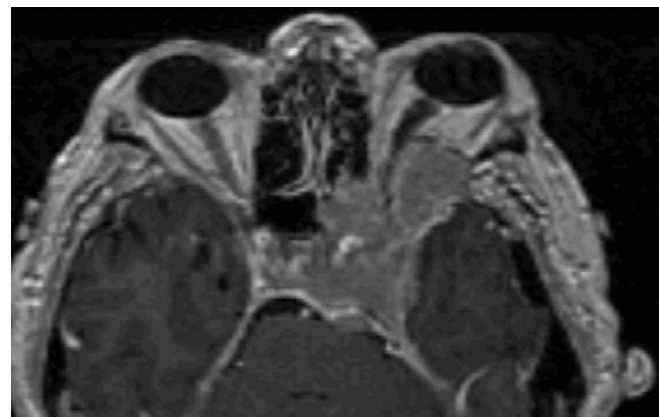

Figure 2 - MRI Brain T1WI axial cuts revealed aggressive clinoidal meningioma extend to the left orbit

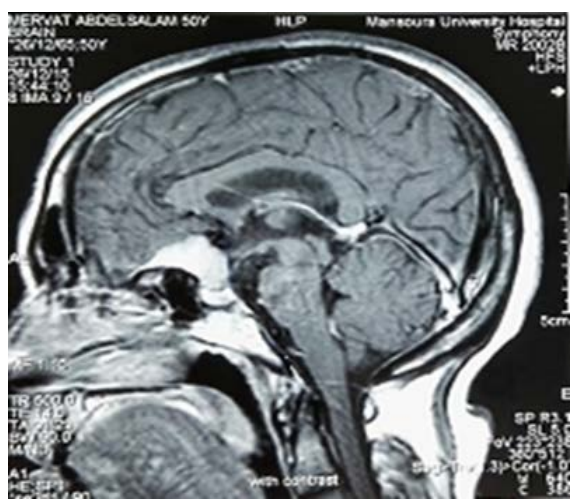

Figure 3 - preoperative MRI brain T1WI sagittal cut with contrast showed dorsum sellae homogenous enhanced meningioma

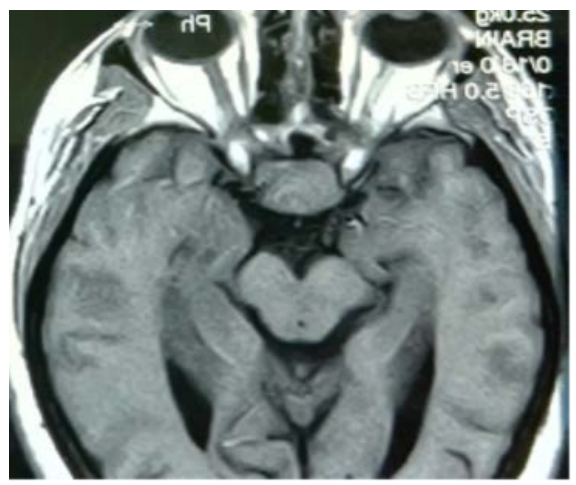

Figure 4 - preoperative MRI brain T1WI axial cut of the same case

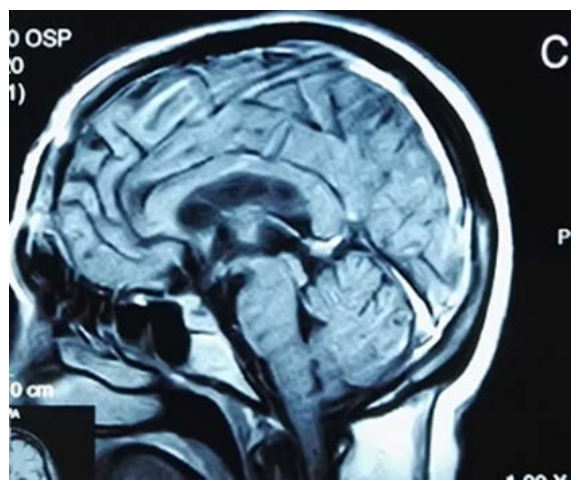

Figure 5 - post-operative MRI brain T1WI sagittal cut with contrast showed complete surgical removal of the dorsum sellae meningioma 


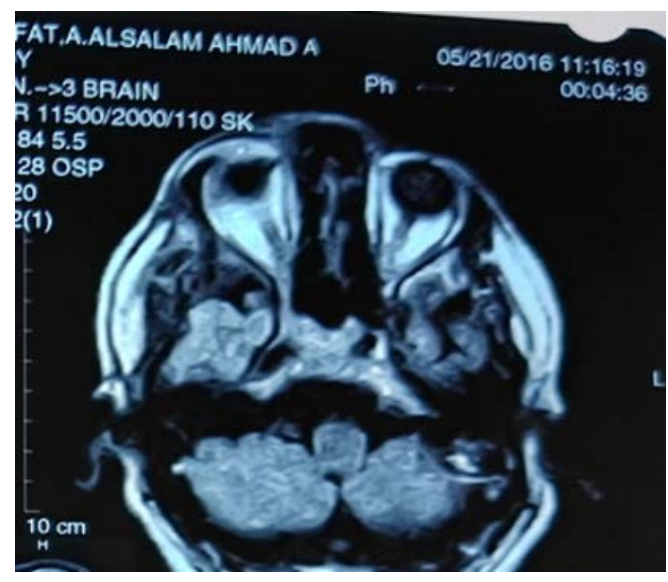

Figure 6 - post-operative MRI brain T1WI axial cut of the same case with no residual tumor

The potential surgical risks increase if these tumors recur after prior surgery with or without irradiation. Proper pre-operative evaluation of the patient clinical, laboratory and imaging study play an important role for proper surgical planning that is crucial for better outcome. Surgical morbidities related to anterior skull base meningiomas are widely addressed in the literature. However; there is infrequent complications related to hypothalamic insult either from direct affection or via manipulation of vascular supply of this area. The aim of this study is to address hypothalamic complications occurred after surgery for anterior skull base meningiomas, pitfalls in our surgical technique and the way to minimize such morbidities $(2,3,4,7,10)$.

\section{Patients and methods}

This retrospective study was conducted in the neurosurgery department, Mansoura university hospitals. All cases with anterior skull base tumors who were operated up on all over the period from 2011 to 2016 were included in the study. All the pre-operative and post-operative data of the patients (clinical, laboratory and radiological) were evaluated. All the operative data were carefully analyzed. The extent of tumor resection and the patient outcome (early and late outcome) was evaluated. All cases that showed transient or permeant hypothalamic dysfunction related to the surgical procedure were included in this study. Out of 182 cases of anterior skull base meningiomas that was operated up on; 9 patients developed either transient or permeant morbidities related to hypothalamic dysfunction.

\section{Results}

Nine cases (4.9\%) out of 182 patients of anterior skull base meningiomas (Table 1) developed approach related hypothalamic morbidities. The complication was transient in 3 cases and permeant in 6 cases (two of them died). Headache was manifest in all patients, visual impairment in 6 patients and behavior changes in one patient of olfactory groove meningioma.

\section{TABLE 1}

\section{Patient characteristics, tumor characteristics}

\begin{tabular}{|l|l|l|l|l|l|}
\hline $\begin{array}{l}\text { Case } \\
\text { number }\end{array}$ & Age & sex & $\begin{array}{l}\text { Meningioma } \\
\text { location }\end{array}$ & $\begin{array}{l}\text { Pre- } \\
\text { operative } \\
\text { C/P }\end{array}$ & $\begin{array}{l}\text { Tumor } \\
\text { size in } \\
\mathbf{m m}\end{array}$ \\
\hline 1 & 43 & F & $\begin{array}{l}\text { Tuberculum } \\
\text { sellae }\end{array}$ & $\begin{array}{l}\text { Headache } \\
\text { Visual } \\
\text { impairment }\end{array}$ & 35 \\
\hline 2 & 51 & F & $\begin{array}{l}\text { Right } \\
\text { Clinoidal }\end{array}$ & $\begin{array}{l}\text { Headache } \\
\text { Visual } \\
\text { impairment }\end{array}$ & 50 \\
\hline
\end{tabular}




\begin{tabular}{|c|c|c|c|c|c|}
\hline 3 & 62 & M & $\begin{array}{l}\text { Diaphragma } \\
\text { sellae }\end{array}$ & $\begin{array}{l}\text { Headache } \\
\text { Visual } \\
\text { impairment }\end{array}$ & 40 \\
\hline 4 & 59 & $\mathrm{~F}$ & $\begin{array}{l}\text { Planum } \\
\text { sphenoidale }\end{array}$ & $\begin{array}{l}\text { Headache } \\
\text { Visual } \\
\text { impairment }\end{array}$ & 40 \\
\hline 5 & 39 & $\mathrm{~F}$ & $\begin{array}{l}\text { Tuberculum } \\
\text { sellae }\end{array}$ & $\begin{array}{l}\text { Headache } \\
\text { Visual } \\
\text { impairment }\end{array}$ & 35 \\
\hline 6 & 63 & M & $\begin{array}{l}\text { Olfactory } \\
\text { groove }\end{array}$ & Headache & 50 \\
\hline 7 & 48 & $\mathrm{~F}$ & Dorsum sellae & $\begin{array}{l}\text { Headache } \\
\text { Visual } \\
\text { impairment }\end{array}$ & 35 \\
\hline 8 & 60 & $\mathrm{~F}$ & $\begin{array}{l}\text { Inner } \\
\text { sphenoid wing }\end{array}$ & Headache & 45 \\
\hline 9 & 59 & M & $\begin{array}{l}\text { Olfactory } \\
\text { groove }\end{array}$ & $\begin{array}{l}\text { Headache } \\
\text { Behavior } \\
\text { changes }\end{array}$ & 65 \\
\hline
\end{tabular}

Among the nine patients who developed surgery related hypothalamic dysfunction; 5 cases were newly diagnosed meningiomas while four cases were recurrent. Two of the recurrent cases recurred after only previous surgery resection while the other cases received radiation (conformal 3D radiotherapy and Gamma Knife Radiosurgery) after initial surgery. Regarding the surgical approach (Table 2) utilized to approach the tumor; 2 cases was operated up on via bifrontal craniotomy, 3 cases via unilateral subfrontal approach, 3 cases via modified cranio-orbito-zygomatic approach and one patient via cranio-orbital approach. Total tumor resection was achieved in 4 cases while intra-capsular debulking was done in 5 cases. In one of the newly diagnosed cases (right clinoidal meningioma); the tumor was engulfing the internal carotid artery and with trial of posterior capsular dissection; bleeding occurred from a perforator of the A1 segment of the anterior cerebral artery that was controlled by bipolar cautery. Another newly diagnosed tumor (dorsum sellae meningioma); total tumor excision was not feasible and during posterior capsular dissection; one of the perforator was injured and unfortunately coagulated. The other 4 cases with only debulking; the tumor was recurrent and there was a lot of adhesion between the tumor capsule and the surrounding neurovascular structures and getting a safe arachnoid plane of dissection was not easily feasible. Total excision was feasible in only one recurrent case (medial sphenoid ridge meningioma). In all the 9 cases; hypothalamic manifestations developed in the early post-operative period. All cases developed diabetes insipidus (transient in 3 cases). 4 cases developed electrolyte disturbances. Impaired heat regulation in occurred 2 cases. Hypocortisolemia occurred in one patients. Impaired level of conscious occurred in two case who died 3 days and one week after surgery.

TABLE 2

Approach and surgery related hypothalamic complication

\begin{tabular}{|l|l|l|l|l|}
\hline $\begin{array}{l}\text { Case } \\
\text { no }\end{array}$ & $\begin{array}{l}\text { Previous } \\
\text { treat } \\
\text { ment }\end{array}$ & $\begin{array}{l}\text { Surgical } \\
\text { corridor }\end{array}$ & $\begin{array}{l}\text { Extent of } \\
\text { resection }\end{array}$ & $\begin{array}{l}\text { Surgery related } \\
\text { hypothalamic } \\
\text { complication }\end{array}$ \\
\hline $\begin{array}{l}\text { 1) } \\
\text { TSM }\end{array}$ & De novo & $\begin{array}{l}\text { Cranio- } \\
\text { orbital }\end{array}$ & Total & Transient DI \\
\hline $\begin{array}{l}\text { 2) Rt } \\
\text { CM }\end{array}$ & De novo & $\begin{array}{l}\text { Modified } \\
\text { COZ }\end{array}$ & $\begin{array}{l}\text { Inracapsular } \\
\text { debulking }\end{array}$ & $\begin{array}{l}\text { DI- electrolyte } \\
\text { disturbances }\end{array}$ \\
\hline $\begin{array}{l}\text { 3) } \\
\text { DSM }\end{array}$ & Surgery & $\begin{array}{l}\text { Rt } \\
\text { subfrontal }\end{array}$ & $\begin{array}{l}\text { Inracapsular } \\
\text { debulking }\end{array}$ & $\begin{array}{l}\text { DI- electrolyte } \\
\text { disturbances- } \\
\text { Hypocortisolemia }\end{array}$ \\
\hline $\begin{array}{l}\text { H) } \\
\text { PSM }\end{array}$ & De novo & $\begin{array}{l}\text { Modified } \\
\text { COZ }\end{array}$ & Total & Transient DI \\
\hline
\end{tabular}




\begin{tabular}{|l|l|l|l|l|}
\hline $\begin{array}{l}\text { 5) } \\
\text { TSM }\end{array}$ & Surgery & $\begin{array}{l}\text { Rt } \\
\text { subfrontal }\end{array}$ & $\begin{array}{l}\text { Inracapsular } \\
\text { debulking }\end{array}$ & DI \\
\hline $\begin{array}{l}\text { 6) } \\
\text { OGM }\end{array}$ & De novo & $\begin{array}{l}\text { Bifrontal } \\
\text { craniotomy }\end{array}$ & Total & DI \\
\hline $\begin{array}{l}7) \\
\text { DSM }\end{array}$ & De novo & $\begin{array}{l}\text { Rt } \\
\text { subfrontal }\end{array}$ & $\begin{array}{l}\text { Inracapsular } \\
\text { debulking }\end{array}$ & $\begin{array}{l}\text { DI- electrolyte } \\
\text { disturbances- } \\
\text { impaired heat } \\
\text { regulation- Died }\end{array}$ \\
\hline $\begin{array}{l}\text { 8) } \\
\text { inner } \\
\text { SWM }\end{array}$ & $\begin{array}{l}\text { Surgery- } \\
\text { RT }\end{array}$ & $\begin{array}{l}\text { Modified } \\
\text { COZ }\end{array}$ & Total & Transient DI \\
\hline $\begin{array}{l}\text { 9) } \\
\text { OGM }\end{array}$ & $\begin{array}{l}\text { Surgery- } \\
\text { RT }\end{array}$ & $\begin{array}{l}\text { Bifrontal } \\
\text { craniotomy }\end{array}$ & $\begin{array}{l}\text { Inracapsular } \\
\text { debulking }\end{array}$ & $\begin{array}{l}\text { DI- electrolyte } \\
\text { disturbances- } \\
\text { impaired heat } \\
\text { regulation- Died }\end{array}$ \\
\hline
\end{tabular}

\section{Discussion}

Meningiomas in the parasellar region represent a great neurosurgical challenge considering highly critical surrounding structures including the neurovascular structures, the hypothalamus, the pituitary gland and its stalk. Important neurovascular structures include the carotid artery and its branches, in some cases the basilar artery and its branches, the optic pathway and cranial nerves within the cavernous sinus. The consistency, vascularity and arachnoid plane of dissection play an important role in the potential feasibility for safe tumor resection. If these tumors are recurrent after surgery with or without additional radiation; the potential surgical risks increase $(1,3,6,8,11,12)$.

The goal of treatment of such meningiomas should be total tumor resection without endangering the surrounding critical structures. With accumulating surgical experience, learning curve development and improvement in the surgical techniques; resection of meningiomas and other parasellar tumors becomes more safely feasible. The initial step for successful surgery for these lesion is proper patient position and adequate approach selection. Appropriate approach selection means not only adequate tumor resection but also help the resection to be safe with minimal morbidities and better deal with any intra-operative complications. Approaching basal meningiomas necessitate good tumor visualization, minimal brain retraction and feasibility of tumor dissection from important adjacent structures. In our early cases we used the traditional approaches including the unilateral or bilateral subfrontal approaches and pterional approach. Although such approaches are enough for good tumor visualization, but it necessitates more brain retraction and in many cases the angle of microscopic visualization is hindered by orbital ridge adding challenge to the safety of adequate tumor removal. By improving the learning curve and better surgical facilities; we prefer more basal approaches using the cranioorbital and cranio-orbito-zygomatic approach (Figures 7, 8,9) which tremendously improved our visualization by providing unobstructed access to the anterior fossa floor from planum to the sella and hence increased our capabilities for safe tumor resection (Figures $10,11,12,13)$ and better function outcome. In our series; we have found that the hypothalamic morbidities occurred not only more frequent but more severe with the traditional approach rather than with the extended transbasal approach and the two cases of mortalities occurred with unilateral and bilateral subfrontal craniotomy $(2,3,4,6$, $7,9,10,12)$. 

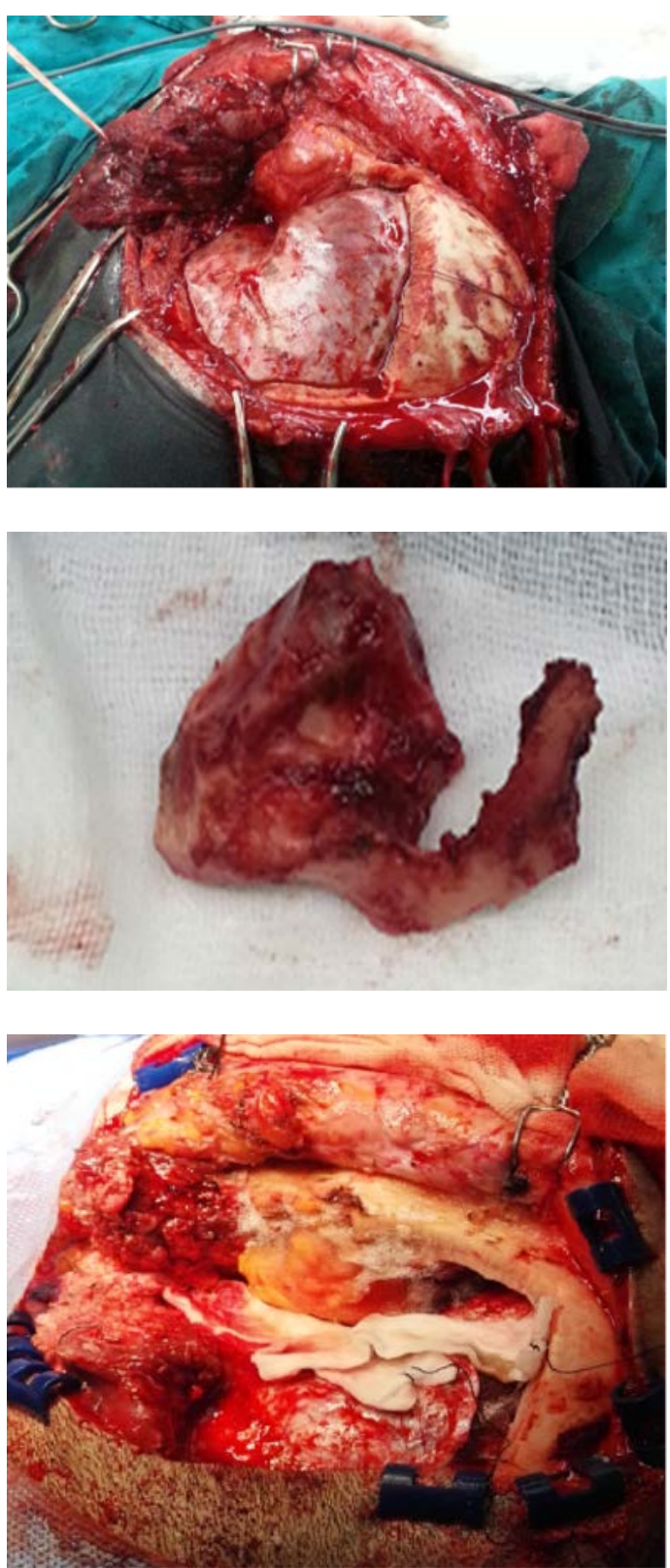

Figures 7, 8, 9 - Intra operative pictures of OrbitoZygomatic Approach in one of our cases

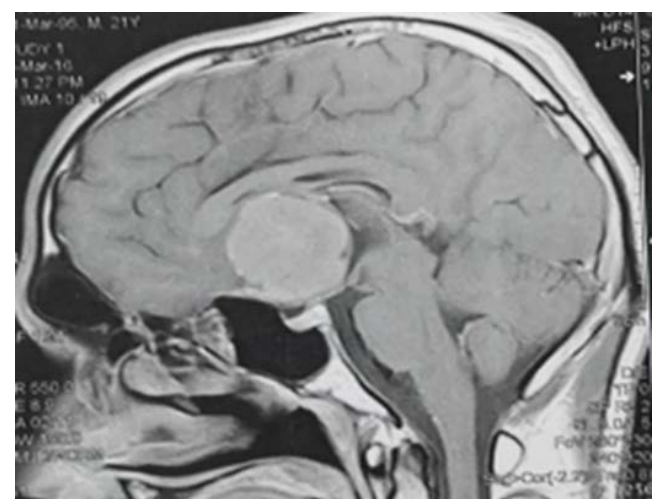

Figure 10 - pre-operative MRI brain T1WI sagittal cut

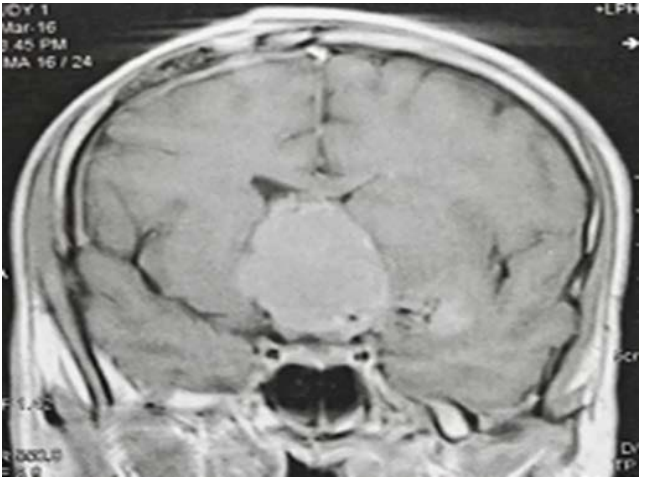

Figure 11 - MRI brain T1WI coronal cut represent a patient had planum sphenoidal meningioma

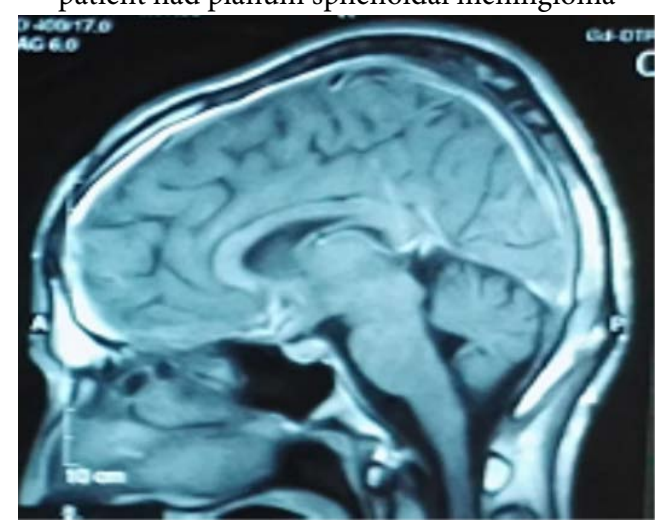

Figure 12 - post-operative MRI brain post contrast T1WI sagittal cut 


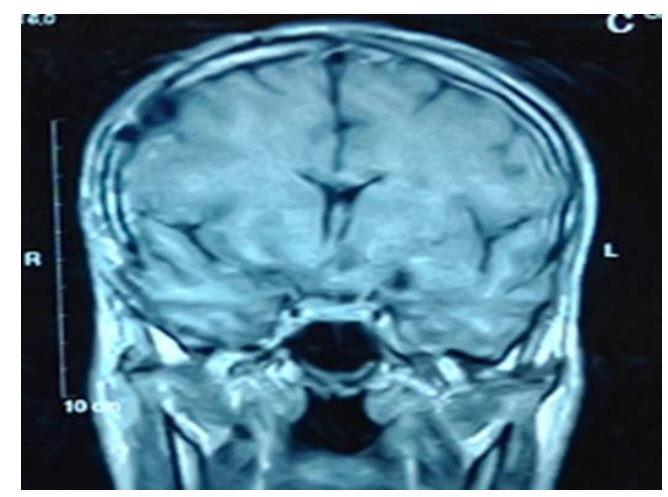

Figure 13 - MRI brain T1WI coronal cut represent a complete removal of the planum sphenoidal meningioma without hypothalamic infarcture that goes with post -operative patients good condition

There are some surgical principles in basal meningioma surgery that facilitate tumor resection without affecting the surrounding structures. First of all adequate skull base bone removal by high speed drill especially greater wing of sphenoid, anterior clinoid process and zygomatic arch in $\mathrm{COZ}$ approach, this step gave us more room for manipulation without any brain retraction in addition to get wide visual angle when using the microscope. Opening the basal cistern for CSF drainage allowing tumor exposure with minimal need to apply brain retraction as a result of reduction of brain volume by subtract large portion of CSF volume that surround the tumor freeing it from neighbor structures especially in presence of arachnoid plane (Liliequist membrane) integrity as in most cases. Generous opening of the sylvian fissure from distal to proximal part then deeper by arachnoid knife \& micro scissor also facilitate tumor exposure and delineating its relationship to the carotid artery and its important branches (Figures 14, 15, 16). With opening the sylvian fissure; the dome \& posterior capsule of the tumor comes to our vision and all the important perforators along it are easily identified which wouldn't be feasible if we are approaching midline meningiomas via the classic sub frontal approach without sylvian fissure dissection. Adequate intracapsular tumor debulking is mandatory before attempting capsular dissection and following the arachnoid plane of dissection is crucial for safe surgical removal of those meningiomas. Absence of arachnoid plane of dissection specially in recurrent meningiomas after previous surgery with or without radiation add more risk to the surgery and increased the chance for post-operative morbidities. Another important point is to minimize the bipolar coagulation especially at the posterior capsule where the important perforators of the anterior cerebral artery especially those supplying the hypothalamus lie. This can minimize the risk for postoperative hypothalamic sequalae. Capacious irrigation during basal meningioma surgery is very important. It facilitates tumor capsule dissection, minimize the need for excessive cauterization and prevent thermal trauma to the important vascular perforators specially those along the posterior capsule $(1,2,4,5,7$, $8,11,12)$ 

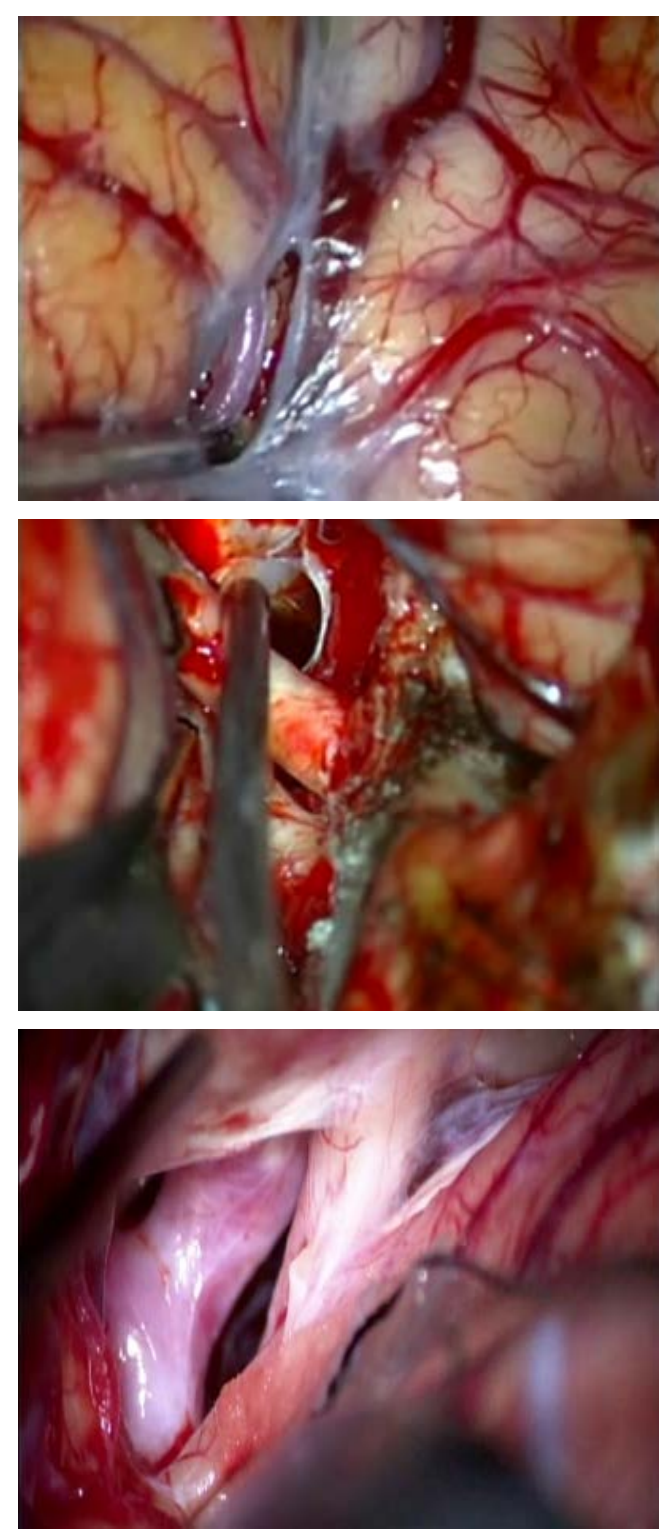

Figures 14, 15, 16 - Intraoperative microscopic picture for Sylvian fissure opening (from distal to proximal) to show both optics and carotid

In our cases with hypothalamic complication; we have four recurrent meningiomas and two of them received radiation after the initial surgical resection and intra-operatively there was no arachnoid plane of dissection was feasible. Total excision was only achieved in one case and one case died related to hypothalamic morbidities after surgery. Also, we have another case of mortality in a newly diagnosed dorsum sellae meningioma that was operated via right sub frontal craniotomy. During posterior capsular dissection; injury occurred to one of the perforators in the posterior capsule that was coagulated, and the patient also died from hypothalamic sequalae. (Figures 17, 18, 19, 20, 21)

One of the critical factors that augment the chance of hypothalamic infarcture was over dehydration because of cessation of microcirculation in end perforators to vital brain structures like hypothalamus as a result of reduction of intravascular volume with subsequence reduce the blood perfusion pressure. We gave this issue our attention in our cases through avoidance of lowering the CVP (Central Venous Pressure) than 4 C.M $\mathrm{H} 2 \mathrm{O} 2$ from the level of the sternum. (Figures $22,23,24,25)$

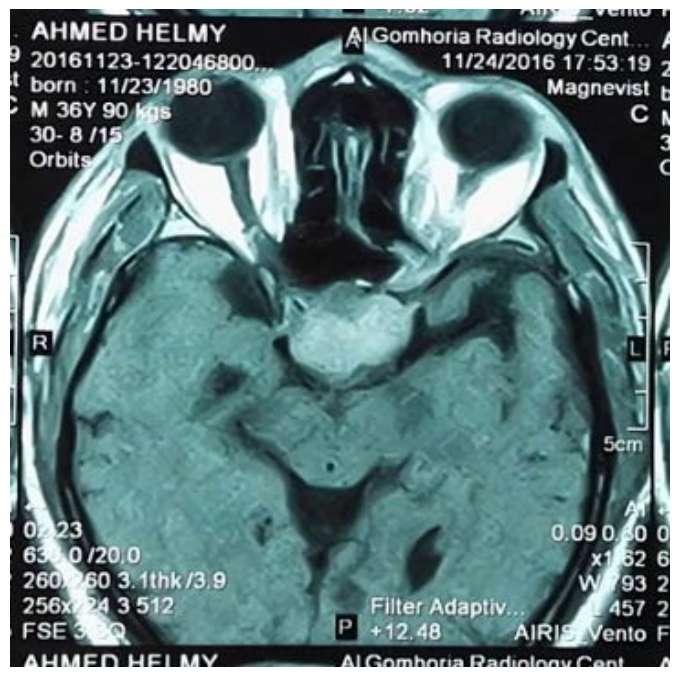



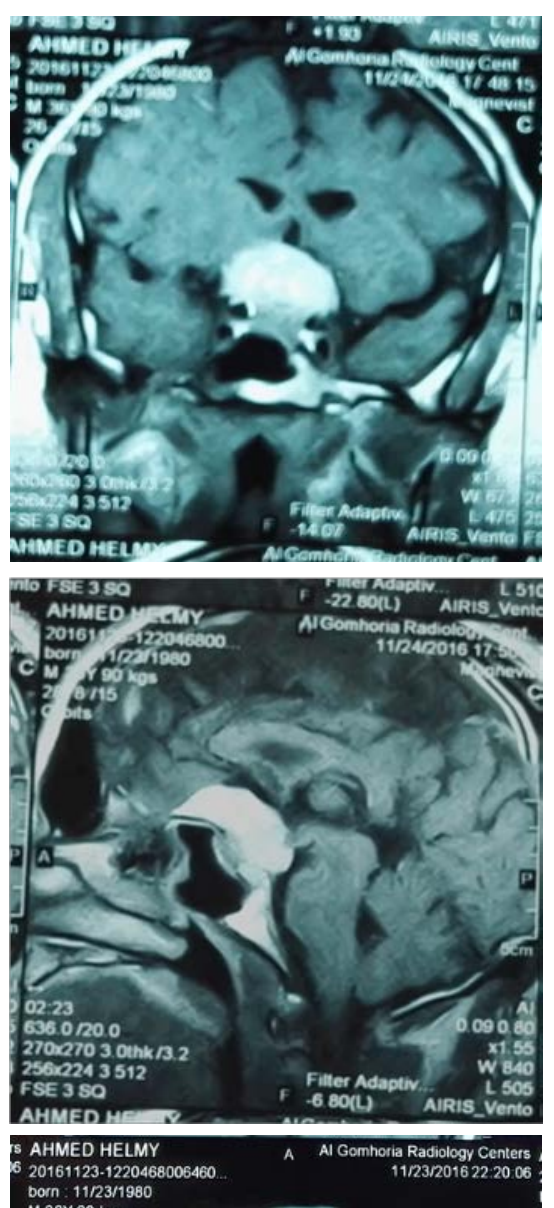

$$
\begin{aligned}
& M 36 \mathrm{Y} 90 \mathrm{kgs} \\
& 15.10 / 12 \mathrm{DS}
\end{aligned}
$$

$$
\begin{aligned}
& \text { 15- } 10 / 120 \\
& \text { Orbits }
\end{aligned}
$$

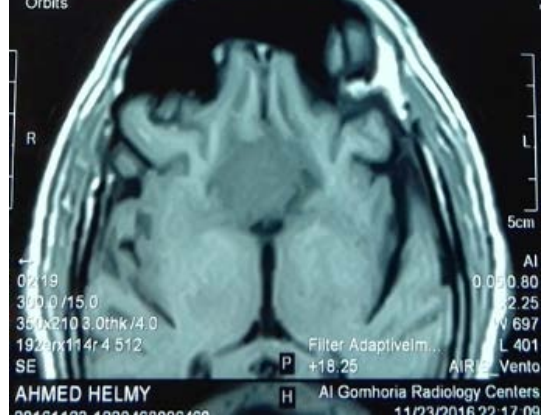

Figures 17, 18, 19, 20 - Preoperative MRI brain T1WI (axial, coronal and sagittal) cuts with contrast demonstrate homogenous enhanced dorsum sellae meningioma while Figure 17 MRI brain T1WI of the same tumor

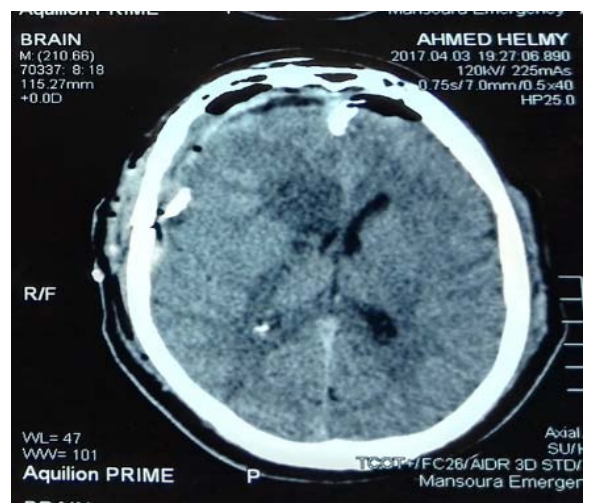

Figure 21 - postoperative CT brain axial cut showed right hypothalamic hypodese area represented infarction that was the cause of the patient's mortality
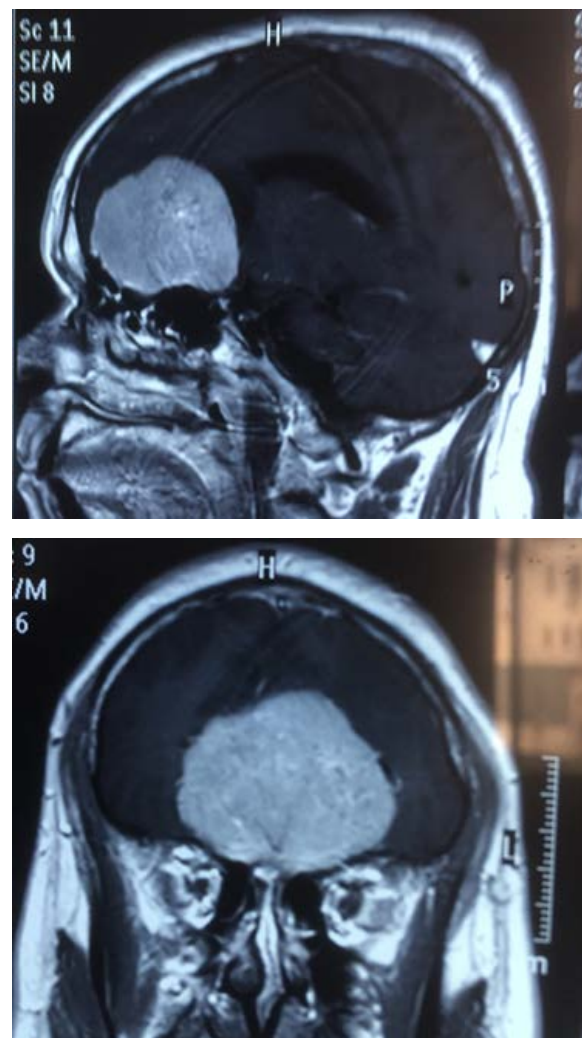

Figures 22, 23 - Preoperative MRI brain T1WI

(sagittal, coronal and cuts with contrast demonstrate homogenous enhanced olfactory groove meningioma 


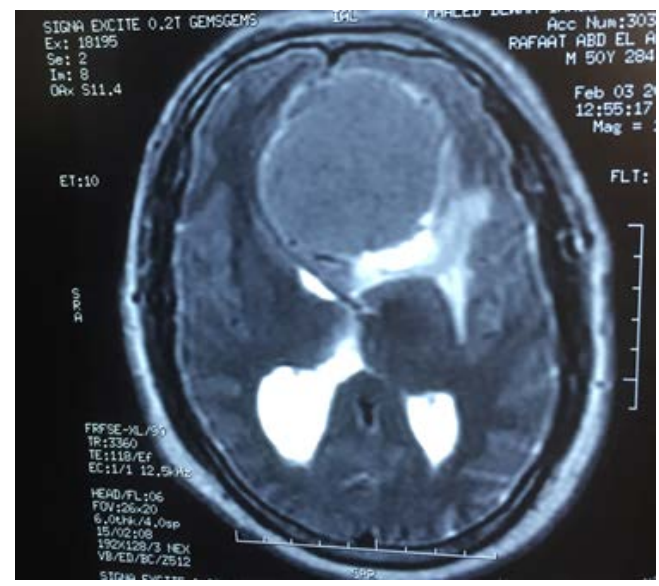

Figure 24 MRI brain T2WI of the same tumor

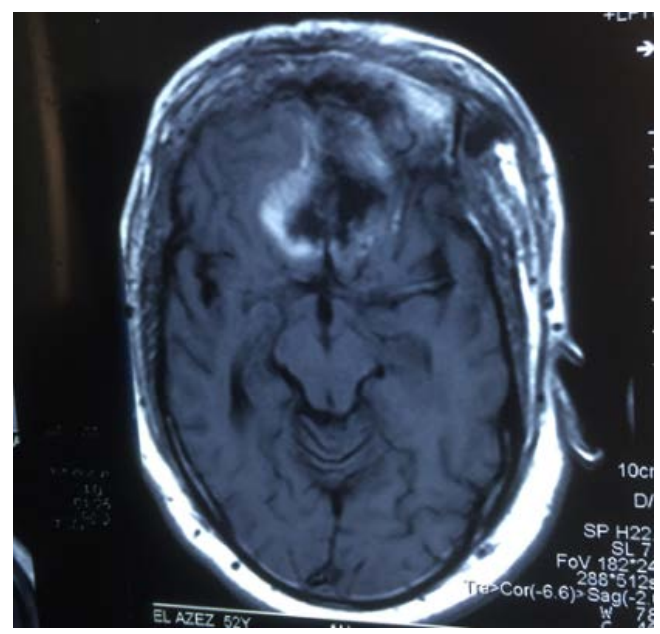

Figure 25 - post-operative MRI brain post contrast T1WI sagittal cut represent a complete removal of the olfactory groove meningioma by $\mathrm{COZ}$ approach and moderate dehydration (CVP 4 C.M H2O2without hypothalamic infarcture that goes with post operative patients good condition

\section{Conclusion}

Through reviewing these cases we can address many critical points:

-Surgery for anterior skull base meningioma is challenging no matter the size of the tumor
- Good anatomical orientation, adequate training and progressive learning curve is crucial

-Careful studying of all the pre-operative imaging is important to get all the useful information regarding tumor characteristic and its extension

-The goal of surgery should be safe total tumor excision if feasible

-We can address the importance of many factors in the tumours especially size, morphology, recurrence who increase hypothalamic insults. factors in surgery include preservation of arachnoid plain, perforators, meticulous dissection for minimize this complication

-Adequate reconstruction is important step of surgery that significantly affect the outcome.

\section{Correspondence}

Ashraf El Badry, M.D., IFAANS

Address: Department of Neurological Surgery

Mansoura University Hospital, Egypt Email

Address: Ashrafbadry@Hotmail.Com or

Ashrafbadry@Mans.Edu.Eg

Phone: +201111300033 or +201223477444

\section{References}

1. Adachi K, Kawase T, Yoshida K, Yazaki T, Onozuka S (2009) ABC Surgical Risk Scale for skull base meningioma: a new scoring system for predicting the extent of tumor removal and neurological outcome. Clinical article. J Neurosurg 111:1053-1061

2. Bassiouni H, Asgari S, Sandalcioglu IE, Seifert V, Stolke D, Marquardt G (2009) Anterior clinoidal meningiomas: functional outcome after microsurgical resection in a consecutive series of 106 patients. Clinical article. J Neurosurg 111:1078-1090

3. Bassiouni H, Asgari S, Stolke D. Tuberculum sellae meningioma; functional outcome in a consecutive series 
treated microsurgically. Surg Neurol 2006;66(1):37-44, discussion 44-45

4. C.A. Bowers, T. Altay, W.T. Couldwell Surgical decision-making strategies in tuberculum sellae meningioma resection Neurosurg Focus, 30 (2011), p. E1 5. Fahlbusch R, Schott W. Pterional surgery of meningiomas of the tuberculum sellae and planum sphenoidale: surgical result with special consideration of ophthalmological and endocrinological outcomes. J Neurosurg 2002;96(2):235-243

6. Fatemi N, Dusick JR, de Paiva, Neto MA Malkasian D, Kelly DF: Endonasal versus supraorbital keyhole removal of craniopharyngiomas and tuberculum sellae meningiomas. Neurosurgery64:5 Suppl 2269 286, 2009

7. Leland Rogers, MD, Igor Barani, MD, Marc Chamberlain, MD, Thomasj. Kaley, MD, Michael McDermott, MD, Jeffrey Raizer, MD, David Schiff, MD, Damien C. Weber, MD, Patrick Y.Wen, MD, and Michael A. Vogelbaum, MD, PhD. (2015) Meningiomas: knowledge base, treatment outcomes, and uncertainties. A RANO review. Journal of Neurosurgery 122:1, 4-23.

8. Margalit N, Kesler A, Ezer H, Freedman S, Ram Z.: Tuberculum and diaphragma sella meningioma- surgical technique and visual outcome in a series of 20 cases operated over a 2.5-year period Acta Neurochir (Wien) 2007;149(12):1199-1204

9. Nanda A, Ambekar S, Javalkar V, Sharma M. Technical nuances in the management of tuberculum sellae and diaphragma sellae meningiomas. Neurosurg Focus. 2013;35(6):E7

10. Shrivastava RK, Sen C, Costantino PD, Della Rocca R: Sphenoorbital meningiomas: surgical limitations and lessons learned in their long-term management. J Neurosurg 103:491-497, 2005

11. Song SW, Kim YH, Kim JW, Park CK, Kim JE, Kim DG, Koh YC, Jung HW: Outcomes After Transcranial and Endoscopic Endonasal Approach for Tuberculum Meningiomas-A Retrospective Comparison. World Neurosurg. 2018 Jan; 109: e434-e445.

12. van Alkemade H, de Leau M, Dieleman EM, Kardaun JW, van Os R, Vandertop WP, van Furth WR, Stalpers LJ (2012) Impaired survival and long-term neurological problems in benign meningioma. Neuro Oncol 14:658-666. 